\section{The High-Tech}

Investment Boom and Economic Growth in

\section{the 1990s: Accounting for Quality}

\author{
Michael R. Pakko
}

$\mathbf{P}$ urchases of computers, software, and communications equipment grew rapidly during the 1990s, representing an increasing share of total U.S. investment spending over the course of the decade. Using official statistics from the U.S. Bureau of Economic Analysis (BEA), nominal investment expenditures for three categories-computers and peripheral equipment, software, and communications equipment-rose to account for over onethird of total business fixed investment by the year 2000, up from only one-fifth a decade earlier. In real, price-adjusted terms, the dramatic rise in spending on these information and communications technologies (ICT) has been even more pronounced: the ratio of real ICT expenditures to real business fixed investment rose from about 15 percent in 1990 to nearly 50 percent in $2000 .^{1}$

This surge in ICT spending was, in turn, a notable feature of the investment boom and rapid economic growth of the late 1990s. From 1995 through 2000, business fixed investment accounted for nearly 32 percent of the total growth of real gross domestic product (GDP). In contrast, investment spending had accounted for only 15 percent of growth during the 1970s and 1980s.

One factor that is potentially important for interpreting the rapid growth of ICT spending in the 1990s is the use of improved methods for measuring quality change, particularly for components of ICT investment spending. As a result of these quality adjustments, the growth rate of reported ICT spending is much higher than the growth rate of the number of unit sales. This is entirely appropriate. A typical personal computer purchased in 2002 , for example, is clearly not directly compara-

Michael R. Pakko is a senior economist at the Federal Reserve Bank of St Louis. Rachel Mandal provided research assistance.

(C) 2002, The Federal Reserve Bank of St. Louis. ble to one purchased a decade ago without some adjustment for advances in the computing power of newer models.

In addition to computers and peripheral equipment, the BEA explicitly accounts for quality improvement in calculating the growth rates of some components of computer software and for telephone switching equipment. ${ }^{2}$ Hence, in calculating the measured real growth rate of ICT investment spending, official statistics are carefully constructed to account for quality improvement.

The fact that ongoing quality improvement is explicitly measured for these ICT sectors-but not so for many other components of investment spending-raises the question of whether the quality adjustment itself might be responsible for the observed prominence of high-tech investment during the 1990s: Is the higher economic growth associated with high-tech investment an artifact of the methodology used to construct recent data, or does it truly represent a departure from the past? ${ }^{3}$

One way to address this question would be to consider adjusted measures of investment that abstract from quality change in the ICT components. However, given the evident recent advances in computing and communications technologies, quality adjustment for these categories is clearly appropriate. Using fixed prices to evaluate growth in the ICT sectors would drastically understate true economic growth. An alternative approach to evaluating the role of quality improvement would be to adjust nonICT investment data for quality improvement that might not be reflected in the official statistics, creating aggregate measures of investment that account for quality improvements across the board.

This paper undertakes such an exercise. Specifically, I extrapolate data from Gordon's (1990) detailed study, The Measurement of Durable Goods Prices, to

\footnotetext{
1 The ICT measures used in this paper include the categories of computers and peripheral equipment, software, and communication equipment. These are three of the six categories that comprise the set of investment goods known as information processing equipment and software. The three remaining elements of this measure are instruments, photocopy and related equipment, and office and accounting equipment.

2 See Landefeld and Grimm (2000) and Landefeld and Fraumeni (2001).

3 Landefeld and Grimm (2000) examine this question as well. Citing the consistency with which quality-adjustment measures have been applied to ICT investment categories, they suggest that the measurement of quality has not, in fact, distorted measures of investment spending. This article goes further to investigate the role of quality change by incorporating sources of quality improvement that are unmeasured in other categories of investment
} 


\section{Table 1}

Output and Investment: Growth Rates and Contributions of Investment to GDP Growth for NIPA Data

\begin{tabular}{|c|c|c|c|c|c|c|}
\hline & 50s & $60 \mathrm{~s}$ & 70s & 80s & 90s & 95-00 \\
\hline \multicolumn{7}{|l|}{ Growth rates } \\
\hline GDP & 3.53 & 4.19 & 3.23 & 3.21 & 3.25 & 4.11 \\
\hline Nonresidential fixed investment & 3.04 & 6.52 & 5.45 & 3.40 & 7.84 & 10.58 \\
\hline Structures & 4.15 & 4.47 & 3.46 & 0.84 & 1.65 & 5.43 \\
\hline Equipment and software & 2.41 & 7.80 & 6.63 & 4.88 & 10.19 & 12.37 \\
\hline IP equipment and software & 9.04 & 14.96 & 15.37 & 11.63 & 16.44 & 20.60 \\
\hline $\mathrm{ICT}$ & 14.34 & 20.04 & 17.48 & 14.45 & 19.63 & 24.51 \\
\hline \multicolumn{7}{|c|}{$\begin{array}{l}\text { Contribution to GDP growth } \\
\text { Percentage points (percent of GDP growth) }\end{array}$} \\
\hline GDP & $\begin{array}{c}3.53 \\
(100.00)\end{array}$ & $\begin{array}{c}4.19 \\
(100.00)\end{array}$ & $\begin{array}{c}3.23 \\
(100.00)\end{array}$ & $\begin{array}{c}3.21 \\
(100.00)\end{array}$ & $\begin{array}{c}3.25 \\
(100.00)\end{array}$ & $\begin{array}{c}4.11 \\
(100.00)\end{array}$ \\
\hline Nonresidential fixed investment & $\begin{array}{c}0.27 \\
(7.58)\end{array}$ & $\begin{array}{c}0.62 \\
(14.82)\end{array}$ & $\begin{array}{c}0.58 \\
(18.12)\end{array}$ & $\begin{array}{c}0.39 \\
(12.15)\end{array}$ & $\begin{array}{c}0.88 \\
(27.11)\end{array}$ & $\begin{array}{c}1.25 \\
(30.37)\end{array}$ \\
\hline Structures & $\begin{array}{c}0.15 \\
(4.12)\end{array}$ & $\begin{array}{c}0.16 \\
(3.85)\end{array}$ & $\begin{array}{c}0.13 \\
(4.14)\end{array}$ & $\begin{array}{l}0.03 \\
(0.78)\end{array}$ & $\begin{array}{c}0.04 \\
(1.25)\end{array}$ & $\begin{array}{c}0.16 \\
(3.89)\end{array}$ \\
\hline Equipment and software & $\begin{array}{c}0.12 \\
(3.46)\end{array}$ & $\begin{array}{c}0.46 \\
(10.97)\end{array}$ & $\begin{array}{c}0.45 \\
(13.98)\end{array}$ & $\begin{array}{c}0.36 \\
(11.36)\end{array}$ & $\begin{array}{c}0.84 \\
(25.84)\end{array}$ & $\begin{array}{c}1.09 \\
(26.44)\end{array}$ \\
\hline IP equipment and software & $\begin{array}{c}0.06 \\
(1.74)\end{array}$ & $\begin{array}{c}0.17 \\
(4.04)\end{array}$ & $\begin{array}{c}0.27 \\
(8.44)\end{array}$ & $\begin{array}{c}0.32 \\
(10.10)\end{array}$ & $\begin{array}{c}0.58 \\
(17.77)\end{array}$ & $\begin{array}{c}0.78 \\
(18.90)\end{array}$ \\
\hline ICT & $\begin{array}{c}0.04 \\
(1.18)\end{array}$ & $\begin{array}{c}0.14 \\
(3.33)\end{array}$ & $\begin{array}{c}0.21 \\
(6.42)\end{array}$ & $\begin{array}{c}0.30 \\
(9.26)\end{array}$ & $\begin{array}{c}0.55 \\
(16.98)\end{array}$ & $\begin{array}{c}0.75 \\
(18.38)\end{array}$ \\
\hline
\end{tabular}

construct a quality-adjusted measure of nonresidential fixed investment in equipment and software (NFI-E\&S). I also apply a long-term estimate of quality improvement for nonresidential structures calculated by Gort, Greenwood, and Rupert (1999) to create an adjusted aggregate for total nonresidential fixed investment (NFI). ${ }^{4}$ A comparison of these data with the official measures reported in the national income and product accounts (NIPA) provides a way to evaluate the importance of this measurement issue in evaluating the contribution of high-tech investment spending to recent trends in investment and overall economic growth.

\section{TRENDS IN INVESTMENT AND GROWTH}

It has been widely noted that the strength of the U.S. economy in the late 1990s was largely attributable to a boom in investment spending, particularly for high-technology goods. Table 1 illustrates the significance of investment spending in the 1990s, detailing the contribution of high-tech investment growth to the growth rate of real GDP in comparison with previous decades. ${ }^{5}$ At each level of aggregation, the 1990s stand out as a decade in which investment spending figured prominently in the composition of economic growth. Total nonresidential fixed investment expanded at a rate of 7.8 percent, accounting for nearly a full percentage point of GDP growth over the decade. In contrast, investment growth was only 4.6 percent over the previous four decades, accounting for less than one-half of 1 percent of GDP growth.

The growth rate of equipment and software investment rose to 10.2 percent in the 1990s (up from an average of 5.4 percent in the previous four

\footnotetext{
4 The quality-adjusted data set constructed for this article is available at $<$ www.stls.frb.org/publications/review $>$

5 Contributions to growth reported in this article are averages of annual rates, calculated using the formula used by the BEA - see Moulton and Seskin (1999). An alternative formula for calculating approximate growth contributions over a multi-year horizon is presented in Landefeld and Parker (1997).
} 


\section{Table 2}

Components of Equipment and Software Investment: Growth Rates and Contributions to E\&S Growth for NIPA Data

\begin{tabular}{|c|c|c|c|c|c|c|}
\hline & 50s & $60 \mathrm{~s}$ & 70s & 80s & 90s & 95-00 \\
\hline \multicolumn{7}{|l|}{ Growth rates } \\
\hline Total E\&S growth & 2.41 & 7.80 & 6.63 & 4.88 & 10.19 & 12.37 \\
\hline IP equipment and software & 9.04 & 14.96 & 15.37 & 11.63 & 16.44 & 20.60 \\
\hline ICT & 14.34 & 20.04 & 17.48 & 14.45 & 19.63 & 24.51 \\
\hline Industrial equipment & 3.32 & 6.04 & 3.08 & 0.38 & 4.62 & 4.64 \\
\hline Transportation equipment & 1.79 & 6.60 & 5.04 & 1.60 & 8.20 & 8.28 \\
\hline Other equipment & 1.05 & 6.43 & 4.12 & 1.33 & 4.12 & 5.67 \\
\hline \multicolumn{7}{|c|}{$\begin{array}{l}\text { Contribution to E\&S growth } \\
\text { Percentage points (percent of E\&S growth) }\end{array}$} \\
\hline Total E\&S growth & $\begin{array}{c}2.41 \\
(100.00)\end{array}$ & $\begin{array}{c}7.80 \\
(100.00)\end{array}$ & $\begin{array}{c}6.63 \\
(100.00)\end{array}$ & $\begin{array}{c}4.88 \\
(100.00)\end{array}$ & $\begin{array}{c}10.19 \\
(100.00)\end{array}$ & $\begin{array}{c}12.37 \\
(100.00)\end{array}$ \\
\hline IP equipment and software & $\begin{array}{c}1.09 \\
(45.26)\end{array}$ & $\begin{array}{c}2.78 \\
(35.59)\end{array}$ & $\begin{array}{c}3.74 \\
(56.43)\end{array}$ & $\begin{array}{c}4.25 \\
(87.21)\end{array}$ & $\begin{array}{c}6.96 \\
(68.31)\end{array}$ & $\begin{array}{r}8.80 \\
(71.16)\end{array}$ \\
\hline ICT & $\begin{array}{c}0.74 \\
(30.86)\end{array}$ & $\begin{array}{c}2.28 \\
(29.30)\end{array}$ & $\begin{array}{c}2.81 \\
(42.41)\end{array}$ & $\begin{array}{c}3.89 \\
(79.85)\end{array}$ & $\begin{array}{c}6.63 \\
(65.10)\end{array}$ & $\begin{array}{r}8.56 \\
(69.23)\end{array}$ \\
\hline Industrial equipment & $\begin{array}{c}0.89 \\
(36.82)\end{array}$ & $\begin{array}{c}1.75 \\
(22.40)\end{array}$ & $\begin{array}{c}0.75 \\
(11.30)\end{array}$ & $\begin{array}{c}0.02 \\
(0.33)\end{array}$ & $\begin{array}{c}0.90 \\
(8.85)\end{array}$ & $\begin{array}{c}0.87 \\
(7.02)\end{array}$ \\
\hline Transportation equipment & $\begin{array}{c}0.19 \\
(7.83)\end{array}$ & $\begin{array}{c}1.75 \\
(22.46)\end{array}$ & $\begin{array}{c}1.25 \\
(18.93)\end{array}$ & $\begin{array}{c}0.30 \\
(6.16)\end{array}$ & $\begin{array}{c}1.66 \\
(16.31)\end{array}$ & $\begin{array}{c}1.72 \\
(13.92)\end{array}$ \\
\hline Other equipment & $\begin{array}{c}0.28 \\
(11.47)\end{array}$ & $\begin{array}{c}1.61 \\
(20.59)\end{array}$ & $\begin{array}{c}1.01 \\
(15.28)\end{array}$ & $\begin{array}{c}0.20 \\
(4.18)\end{array}$ & $\begin{array}{c}0.70 \\
(6.86)\end{array}$ & $\begin{array}{c}1.00 \\
(8.08)\end{array}$ \\
\hline
\end{tabular}

decades) and accounted for over 95 percent of the contribution of total investment to GDP growth. Two-thirds of that contribution was attributable to ICT investment. Note that although the growth rate of ICT spending was consistently high over the entire 50-year period-averaging over 17 percent-its contribution to total economic growth has become notable only in recent years as high-tech spending has comprised a larger share of total investment. In the 1960 s, a 20 percent growth rate of ICT spending contributed only 0.14 percent to GDP growth; in the $1990 \mathrm{~s}$ a similar growth rate contributed 0.55 percent.

This feature is also evident in the data presented in Table 2, which details the growth rates of the main subcomponents of equipment and software investment. Table 2 also reveals - somewhat contrary to conventional wisdom - that the importance of the ICT component of equipment investment dates back much earlier than the boom of the past decade. As far back as the 1950s, information processing equip- ment and software accounted for well over one-third of the growth in total equipment and software purchases, exceeding the contributions of each of the other components: industrial equipment, transportation equipment, and other equipment.

In the 1980s, despite a slowdown in growth, information processing equipment and software accounted for nearly 90 percent of the growth in total equipment and software spending. In large part, this is attributable to an even sharper slowdown in the growth rates of the other components. The investment boom of the 1990s is associated with a rebound of growth in all categories of equipment and software investment, but with the share of the information processing and software component having risen to the point that its growth contribution overwhelmed the increases in other categories.

The last columns in Tables 1 and 2 show that these trends were even more pronounced in the latter half of the decade. For example, total spending on equipment and software accelerated to a growth 


\section{Figure 1}

\section{Contributions to Growth of Equipment and Software Investment}

NIPA Data and Forecasts

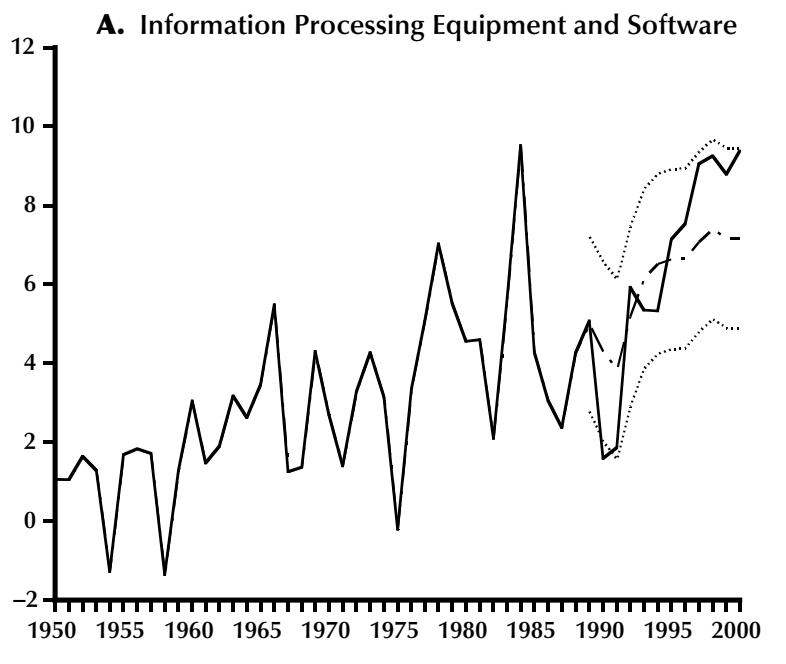

rate of 12.4 percent, accounting for more than onefourth of total GDP growth. ICT spending growth rose to nearly 25 percent, accounting for over twothirds of the growth in total equipment and software spending.

\section{HOW DIFFERENT WERE THE 1990s?}

Clearly, ICT spending, and investment spending more generally, accelerated in the 1990s, accounting for increasing shares of overall economic growth. However, the rising prominence of these components also reflected trends that were evident well before the boom of the last decade. An important question therefore remains: Did the acceleration of the 1990s represent an unusual or exceptional period, or was it simply a continuation of the longerterm evolution of the structure of the U.S. economy?

To address this question, I estimate a set of simple time-series models for the growth contributions of various investment components, using data through 1988. The models are then used to forecast the 1990s, providing a means for evaluating actual growth relative to what might reasonably have been expected ex ante.

The variables to be modeled and forecasted are the growth contributions of investment components to the growth rate of a broader aggregate-either total NFI-E\&S or total GDP - as summarized in the lower panels of Tables 1 and 2. In each case, the growth component is regressed on its own lagged

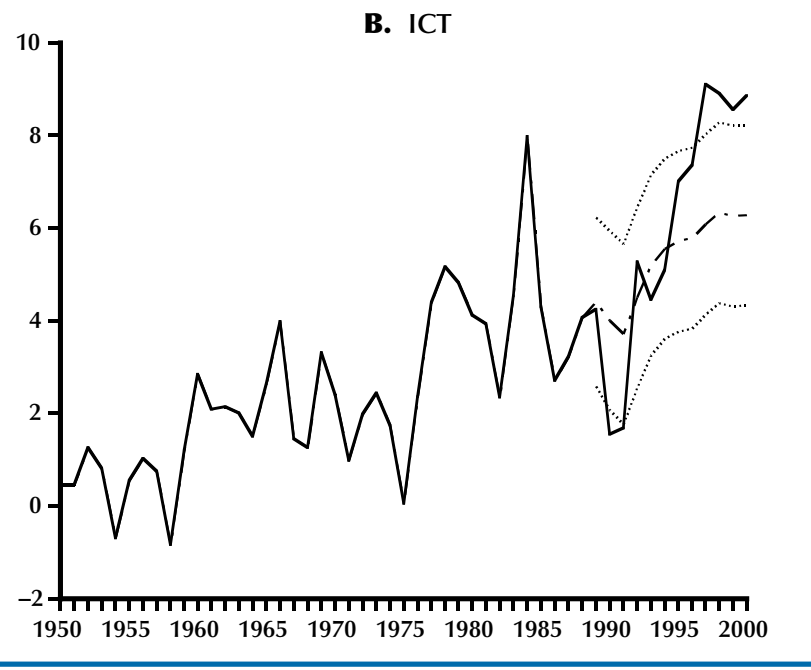

value, a constant, and a time trend. ${ }^{6}$ Cyclical characteristics of the series are modeled by including in the regression the current growth rate of the aggregate to which the growth contribution refers (NFI-E\&S or GDP).

To adjust for problems associated with simultaneous equation bias, the models are estimated with two-staged least squares, using instrumental variables for the aggregate growth rates. ${ }^{7}$ The instruments used are growth rates for subaggregates that include everything in the total aggregate except the component being modeled. 8

Figure 1 shows the contribution of high-tech investment components to total NFI-E\&S growth, along with the forecast for the 1990s from the timeseries models. Panel A focuses on the information processing and software component. The actual growth contribution of this component during the late 1990s exceeded the growth rate forecasted by the model (shown by the dashed line). For 19962000 , the contribution of information processing

\footnotetext{
6 Although the constant and time trend were not significant in all the regressions, both were included in all cases to maintain consistency.

7 Simultaneous equation bias arises because the growth contribution being estimated and forecasted is, by definition, a component of the aggregate growth rate used to capture cyclical behavior on the righthand side of the equation. Consequently, these regressors are likely to be correlated with the error term of the estimation equation.

8 These subaggregates are constructed by "unchaining" the featured component from the aggregate - that is, by a chain-weighted subtraction
} 


\section{Figure 2}

\section{Contributions of Growth of GDP}

NIPA Data and Forecasts
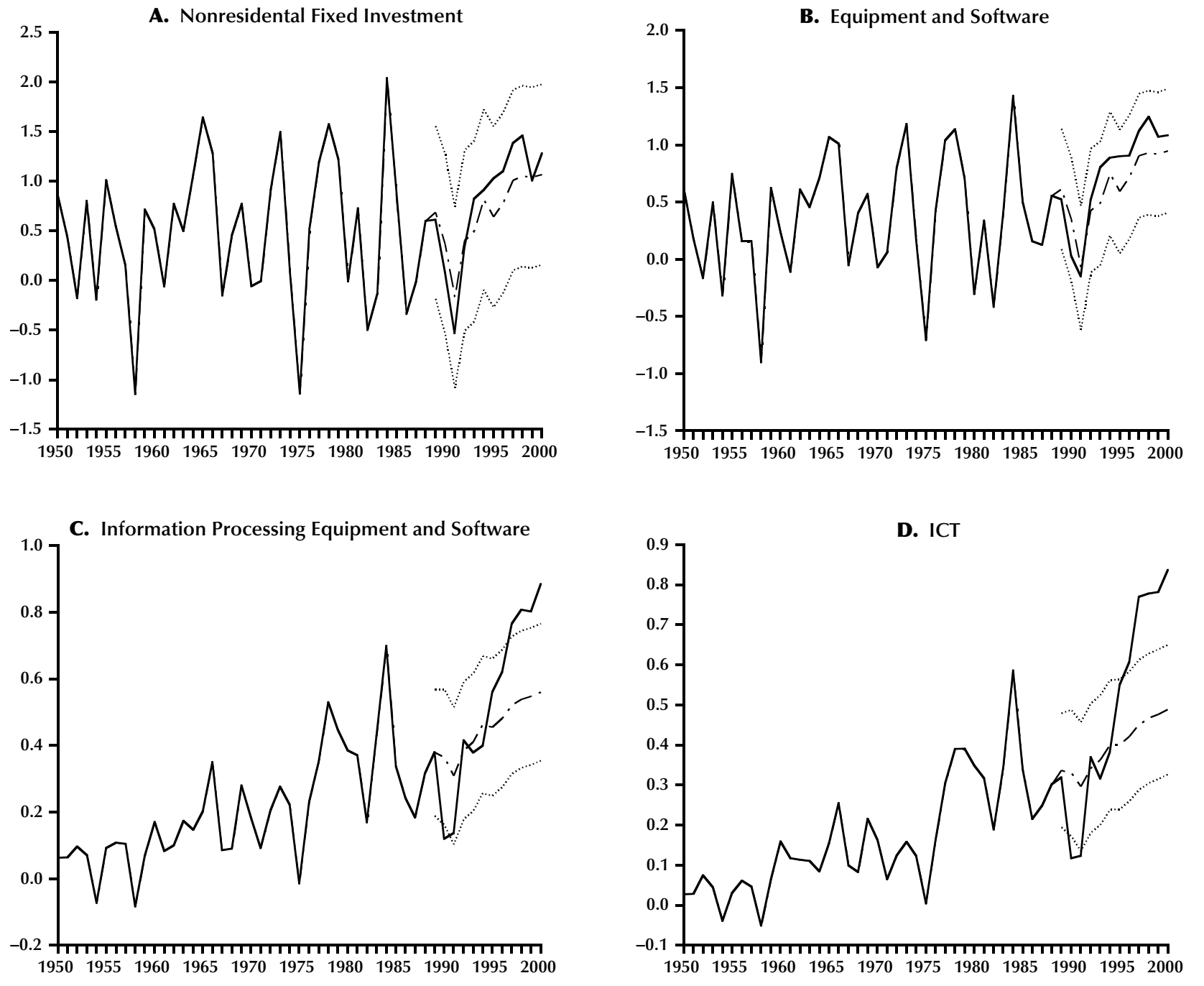

equipment and software to NFI-E\&S averaged 1.7 percentage points more than predicted by the model. Nevertheless, the actual growth contribution remains within the bounds of a confidence interval (dotted lines) representing \pm 2 times the standard errors of the forecast. That is, although information processing equipment and software contributed more to NFI growth in 1996-2000 than would have been predicted by the model, the deviation from expectations is not statistically significant.

Panel B of Figure 1 shows the contribution of ICT investment to equipment and software growth. In this case the actual growth contribution greatly exceeds the forecast in the latter half of the 1990s, surpassing the simulated path by an average of 2.4 percent annually during the 1996-2000 period, and moving outside the confidence interval during that period as well. In this sense at least, the ICT investment boom in the late 1990s did represent a significant departure from the past in terms of the composition of total investment spending.

For each of the measures considered in Figure 1, it is interesting to note that the sharp downturn in high-tech investment growth in the early 1990s slightly exceeds the lower confidence bound for the forecasts. The contribution of high-tech investment 
to overall fixed investment growth was evidently more variable over the most recent business cycle than would have been anticipated from past experience.

Figure 2 shows the actual and forecasted contributions of investment growth - at various levels of disaggregation - to the growth rate of total GDP. The growth contributions of total nonresesidental fixed investment and of equipment and software, shown in panels A and B, respectively, fall slightly below their forecasted values early in the 1990s and are higher than expected throughout the remainder of the decade. From 1996-2000, the actual contributions of these measures to total GDP growth exceeded their forecasted values by 0.25 percent and 0.20 percent, respectively. However, neither investment measure strays far enough away from its forecasted path to move outside its confidence interval.

For more narrow measures of investment focusing on high-tech capital goods, the actual contributions to GDP growth deviated significantly from previous patterns. The contributions of information processing equipment and software and of ICT spending - shown in panels $\mathrm{C}$ and $\mathrm{D}$, respectivelycontributed more to both the downturn of the early 1990s and the boom of the late 1990s than previous trends and fluctuations would have suggested. The contribution of ICT growth to GDP growth, in particular, greatly exceeds the upper confidence bound during 1996-2000.

The time-series analyses illustrated in Figures 1 and 2 suggest that, although the contribution of investment to overall economic growth in the 1990s did rise relative to past growth trends, the deviations are significant only for narrower measures of hightech investment spending. Because it is the qualityadjusted growth contributions of the ICT sectors in particular that significantly accelerated in the late $1990 \mathrm{~s}$, the issue of unmeasured quality change in the other components of investment spending takes on a potentially crucial role in assessing the true importance of high-tech investment spending in the evaluation of recent growth trends.

\section{MEASURING QUALITY CHANGE}

The measurement of quality change has always been important in the construction of the NIPA data. Quality characteristics of newly introduced goods are routinely incorporated into the data using socalled "matching models" that compare the attributes of new and existing products. In recent years, the BEA has implemented several revisions to its methodologies in order to account for the rapid rate of innovation in ICT and other high-tech sectors. In particular, so-called "hedonic regression techniques" have been applied to construct quantity and price indices that adjust for changes in quality over time. (See insert, "Measuring Quality Improvement with Hedonics.") Among the more important applications of this approach, the BEA incorporates hedonic indices for computer equipment and purchased software, telephone switching equipment, cellular services, and video players, among others. ${ }^{9}$ Moreover, the BEA has even changed its aggregation methodology to more accurately measure the contribution of quality change to GDP growth: the adoption in 1996 of a chain-weighting methodology was intended to allow aggregates to track quality improvement better over time.

Nevertheless, some economists contend that a significant amount of quality change goes unmeasured in the official statistics, particularly in cases where quality improvement is more incremental. As detailed in his 1990 book, The Measurement of Durable Goods Prices, Robert Gordon undertook to quantify the extent of this unmeasured quality change. Drawing data from a variety of sources, including special industry studies, Consumer Reports, and the Sears catalog, Gordon compiled a data set of more than 25,000 price observations. Using a number of methodologies-including traditional matching methods, hedonic price index construction, and price comparisons for used capital equipment-he compiled the data into quality-adjusted price indexes for 105 different product categories, then aggregated the data to correspond to the individual components of the BEA's measure of spending on producers' durable equipment. In particular, he calculated "drift ratios," representing the difference between the growth rates of his quality-adjusted price data and the official NIPA price indexes, then aggregated the components to create a new qualityadjusted real investment series.

Table 3 shows long-run averages of Gordon's drift ratios for individual components of investment spending. The table is organized by the contemporary categories and definitions for private NFI-E\&S, which differs somewhat from the taxonomy used at the time that Gordon compiled his data. The growth rates in Table 3 represent the spreads between the official growth rates and the growth rates of Gordon's

\footnotetext{
9 Landefeld and Grimm (2000) report that 18 percent of GDP is estimated using hedonic methods.
} 


\section{MEASURING QUALITY IMPROVEMENT WITH HEDONICS}

As quality improvement in high-tech goods has become increasingly evident, a technique known as "hedonic regression" has been incorporated in the measurement of several categories in the national accounts. A hedonic price indexso named because it attempts to measure the quantity of utility, or pleasure, derived from a particular good-is a statistical technique that adjusts the price of an item to reflect improvements in quality. For example, a personal computer purchased in 2002 might cost the same amount as one purchased a decade earlier, but the newer model is clearly superior in terms of overall computing power.

The hedonic regression approach to quantifying this type of comparison is not a particularly new idea: one of its earliest applications was to the comparison of automobile quality across model years in the 1930s. ${ }^{1}$ It is particularly wellsuited to compare goods that can be thought of as comprising a bundle of underlying attributes, each of which is assumed to have its own intrinsic value.

In the case of personal computers, the components inside the "box" itself have several independent, measurable attributes (e.g., processor speed, memory, disk storage capacity). The hedonic approach estimates the value of these attributes by constructing a regression model relating the prices of computers to data on their underlying attributes.

The value of new computers can be expressed relative to the vintage computers by using values predicted by estimated model parameters. That is, the ratio of nominal expenditures on new computers to their model-predicted prices yields a measure of the real computing power of the new model relative to the older models. Unit production or sales figures for the number of "boxes" would fail to capture this adjustment.

The effect of this methodology on measured quantities and prices can be dramatic. From 1987 to 2000, the ratio of the quality-adjusted price index for final sales of computers and peripheral equipment to the price index for non-computer final sales declined nearly 95 percent. That is, the quantity of computing power purchased with one dollar in 1987 would cost only a nickel by the year 2000 , after accounting for both quality improvement and inflation.

1 Triplett (1986) attributes the origin of hedonics terminology to Court (1939). quality-adjusted measures. Over the span of the entire sample period, 1947-83, the drift ratios are uniformly positive, indicating unmeasured quality improvement. ${ }^{10}$ In many cases, the magnitude of the quality adjustment is remarkable. Not surprisingly, Gordon's estimates of unmeasured quality improvement are particularly large for the high-tech categories of computing and communications equipment (prior to the adoption by the BEA of hedonic methodologies for these categories). Drift ratios for some components of transportation equipment, particularly aircraft, also indicate substantial undermeasurement of quality change over the sample period.

Generally, the magnitudes of the drift ratios are smaller in the later years of the sample period. ${ }^{11}$ This observation is consistent with the hypothesis that the official statistics more accurately measure quality change in the 1970s and 1980s than they did in earlier decades.
The bottom line of Gordon's study was that the official NIPA data understated the true growth rate of investment spending by nearly 3 percentage points over the period 1947-83. The importance of this finding for evaluating recent investment and economic growth is twofold: First, if unmeasured quality improvement caused investment to be understated in the past, more recent growth trends-which do account for a great deal of quality change - might not be so extraordinary after all. In addition, accounting for possible unmeasured quality improvement in the non-ICT components of investment spending should have the effect of diluting the contribution

\footnotetext{
${ }^{10}$ The signs of the drift ratios reported in Table 3 are reversed from those reported in the summary tables in Gordon's book, which report the adjustment to prices rather than quantities.

11 In some cases, the drift ratios are even negative for the 1973-83 period, indicating that the official data capture more quality improvement than is revealed by Gordon's calculations.
} 


\section{Table 3}

Drift in the Ratio of Official to Alternative Deflators for Components of Private Nonresidential Fixed Investment in Equipment and Software

\section{Growth rates (percent)}

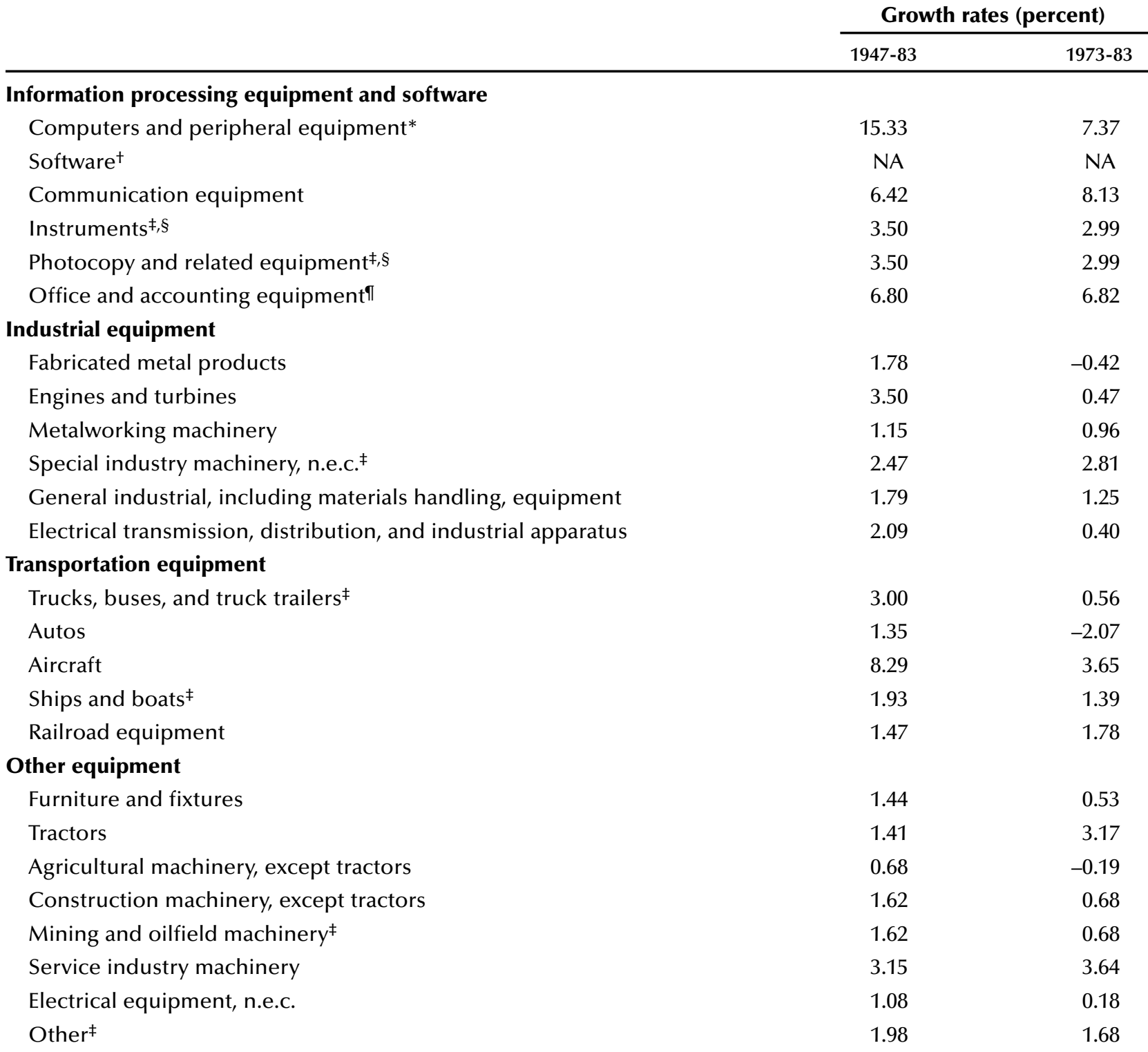

NOTE: *The official BEA statistics now incorporate quality adjustment using a hedonic-price index approach, obviating the need to use Gordon's figures.

†Software expenditures have been included in official measures only since 1999.

₹Classified by Gordon as a "secondary" category, with price data derived from primary categories.

\$At the time of Gordon's study, instruments and photocopy comprised a single component.

IDerived from data on the category of office, computing, and accounting machinery, adjusted to exclude computers and peripherals. n.e.c. $=$ not elsewhere classified.

SOURCE: Gordon (1990), Appendix B, Appendix C, and Tables 6.11 and 6.12. 


\section{Figure 3}

\section{Growth Rates of Major Components of Equipment and Software Investment}

NIPA and Adjusted Data
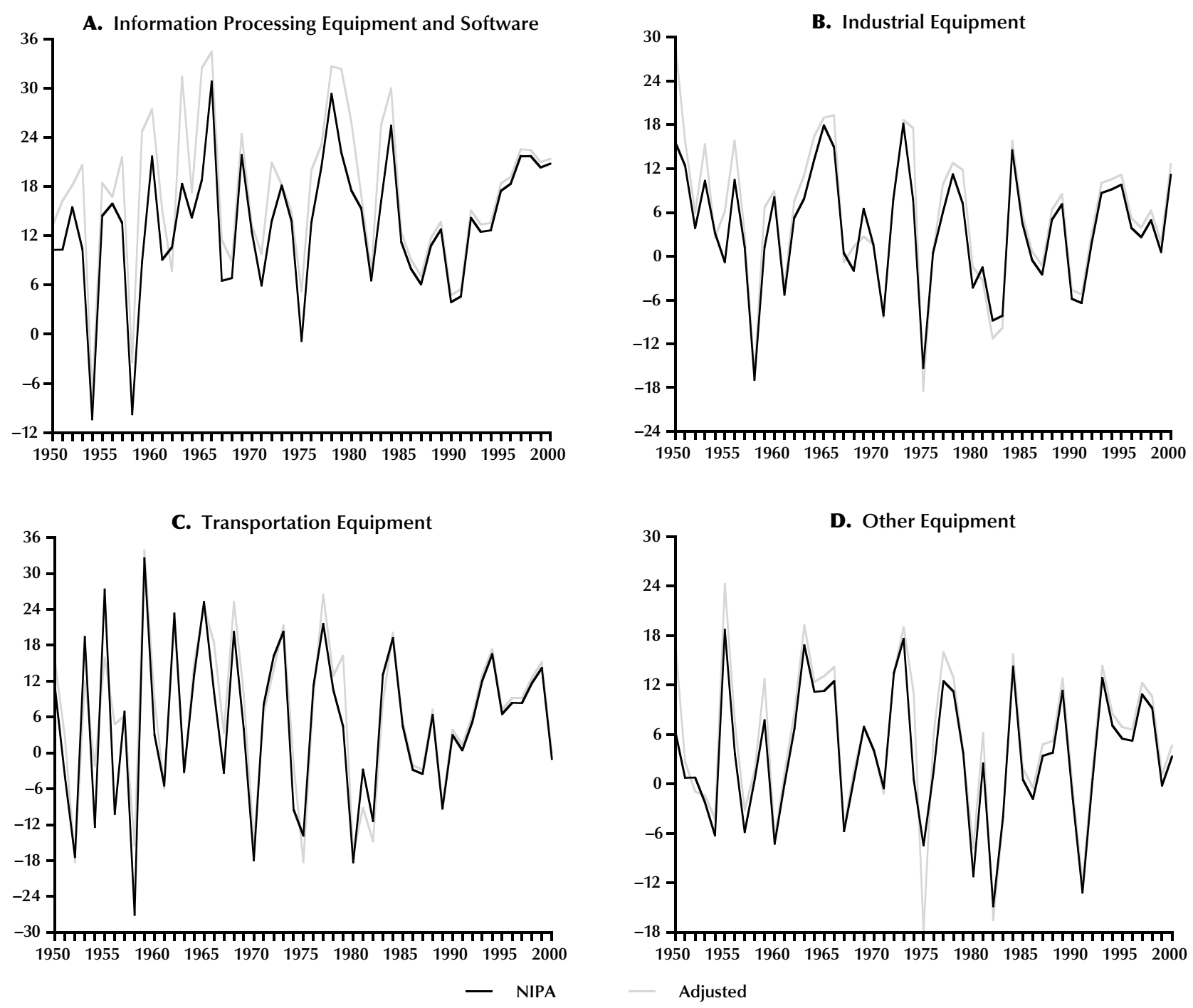

of ICT growth to overall investment and output growth in the recent data.

Unfortunately, because Gordon's data set extends only through 1983 , some extrapolation is necessary to use his findings to evaluate recent U.S. economic experience.

\section{Applying Gordon's Adjustments to Contemporary Data}

In order to apply Gordon's quality adjustment to contemporary NIPA data, it is necessary to make some assumptions about unmeasured quality adjustment in the post-1983 period. In addition, changes in the BEA's definitions and methodology implemented over the past two decades require some attention.

The basic procedure I adopt is to assume that the growth rate of unmeasured technological change over the 1984-2000 period is the same as Gordon's measured drift rate over the last 10 years of his sample: 1973-83. That is, Gordon's actual drift ratios are extrapolated through 2000 using the growth rates in the second column of Table 3 . 


\section{Table 4}

Components of Equipment and Software Investment: Growth Rates and Contributions to E\&S Growth for Adjusted Data

\begin{tabular}{lcccccc} 
& $\mathbf{5 0 s}$ & $\mathbf{6 0 s}$ & $\mathbf{7 0 s}$ & $\mathbf{8 0 s}$ & $\mathbf{9 0 s}$ & $\mathbf{9 5 - 0 0}$ \\
\hline Growth rates & & & & & & \\
Total E\&S growth & 5.77 & 10.08 & 9.14 & 5.73 & 11.22 & 13.36 \\
IP equipment and software & 15.30 & 19.66 & 20.30 & 13.89 & 17.24 & 21.31 \\
$\quad$ ICT & 23.75 & 23.67 & 20.93 & 16.54 & 19.63 & 24.51 \\
$\quad$ Industrial equipment & 6.43 & 7.39 & 5.04 & 0.68 & 5.95 & 5.99 \\
$\quad$ Transportation equipment & 4.82 & 9.37 & 6.99 & 0.75 & 9.11 & 9.19 \\
$\quad$ Other equipment & 3.25 & 7.63 & 5.52 & 2.46 & 5.47 & 7.03 \\
Contribution to E\&S growth & & & & & & \\
Percentage points (percent of E\&S growth) & & & & & & \\
Total E\&S growth & 5.77 & 10.08 & 9.14 & 5.73 & 11.22 & 13.36 \\
& $(100.00)$ & $(100.00)$ & $(100.00)$ & $(100.00)$ & $(100.00)$ & $(100.00)$ \\
Contribution from: & & & & & & \\
IP equipment and software & 1.87 & 3.58 & 4.91 & 5.02 & 7.30 & 9.10 \\
& $(32.35)$ & $(35.51)$ & $(53.79)$ & $(87.70)$ & $(65.05)$ & $(68.12)$ \\
$\quad$ ICT & 1.22 & 2.67 & 3.36 & 4.38 & 6.66 & 8.59 \\
& $(21.09)$ & $(26.45)$ & $(36.81)$ & $(76.47)$ & $(59.38)$ & $(64.35)$ \\
Industrial equipment & 1.84 & 2.15 & 1.26 & 0.05 & 1.17 & 1.12 \\
& $(31.93)$ & $(21.37)$ & $(13.77)$ & $(0.94)$ & $(10.39)$ & $(8.41)$ \\
Transportation equipment & 1.24 & 2.52 & 1.76 & 0.12 & 1.85 & 1.92 \\
& $(21.46)$ & $(24.99)$ & $(19.29)$ & $(2.17)$ & $(16.46)$ & $(14.34)$ \\
Other equipment & 0.86 & 1.92 & 1.34 & 0.43 & 0.94 & 1.24 \\
& $(14.87)$ & $(19.02)$ & $(14.71)$ & $(7.49)$ & $(8.39)$ & $(9.25)$ \\
\hline
\end{tabular}

The drift ratios are extrapolated on a componentby-component basis and then aggregated to create a quality-adjusted measure of total investment spending. ${ }^{12}$ This disaggregated approach is preferable to a simple extrapolation of the aggregate trend for two reasons: First, several changes in the BEA's definitions and methodology have, for some components, eliminated or at least mitigated the measurement problems suggested by Gordon's study. (Specific adjustments for these changes that were made in the data extrapolation are described in the Appendix.) In addition, the procedure of reaggregating the quality-adjusted components using a chainweighting methodology allows the role of changing expenditure shares over time to be appropriately accounted for.

Figure 3 shows annual growth rates for the four main categories of equipment and software, both for the official NIPA data and the quality-adjusted measures constructed as described above. For each category, the growth rates of the adjusted measures exceed those of the NIPA data, but decreasingly so over time. The patterns of fluctuations in the growth rates of these investment components are affected little by the adjustment - the variances of growth rates greatly exceed the magnitude of the quality adjustments.

\section{Unmeasured Quality Change for Nonresidential Structures}

In order to account for unmeasured quality change in the structures component of NFI, I utilize the estimate of Gort, Greenwood, and Rupert (1999) that the quality-improvement in nonresidential structures that is not captured in the official NIPA data amounts to approximately 1 percent growth per year. Consequently, I add 1 percentage point

\footnotetext{
12 A similar approach to extrapolating the Gordon data set forward is described by Cummins and Violante (2002).
} 
to each year's growth rate in real nonresidential structures over the sample period of 1947-2000, constructing an adjusted real series expressed in 1996 chain-weighted dollars. This measure is then aggregated by chain-weighting with the adjusted measure of investment in equipment and software to produce a quality-adjusted measure of total private nonresidential fixed investment.

Figure 4 shows annual growth rates for the official NIPA version of NFI and the quality-adjusted measure. As was the case for the components of equipment and software spending, the effect of the quality adjustment is to shift the growth series upward slightly, without altering the pattern of growth fluctuations evident in the original unadjusted data. On the other hand, the adjustment is clearly larger in the earlier decades of the sample period, which should tend to diminish the importance of the rise in investment spending in the late 1990s relative to earlier decades.

Finally, in order to maintain consistency in the comparison of the official NIPA with quality-adjusted data, and in their contributions to overall economic growth, an alternative quality-adjusted measure of GDP was constructed. This procedure involved unchaining NFI from GDP in the official data, then combining the resulting rest-of-GDP series with the adjusted NFI data by chain-weighting.

\section{INVESTMENT AND GROWTH IN THE QUALITY-ADJUSTED DATA}

Table 4 reports the decade-averages of qualityadjusted growth rates for the major subcomponents of equipment and software spending and their contribution to the aggregate growth rate. Comparing Table 4 with Table 2, the differences between the official and adjusted series appear to be marginal. The quality adjustment raises the average growth rates of all measures of investment, particularly in the earlier decades.

However, the acceleration of growth in information processing and software purchases and, more narrowly, in ICT spending, follows the same general pattern as in the unadjusted data: a trend of accelerating growth rates and increasing contributions to the growth rate of total nonresidential fixed investment.

Similarly, Table 5 shows that the growth rates of quality-adjusted investment and their contributions to GDP growth show the same general patterns as in the official NIPA data summarized in Table 1. The growth rates for all the quality-adjusted mea-

\section{Figure 4}

\section{Growth Rate of Nonresidential Fixed} Investment

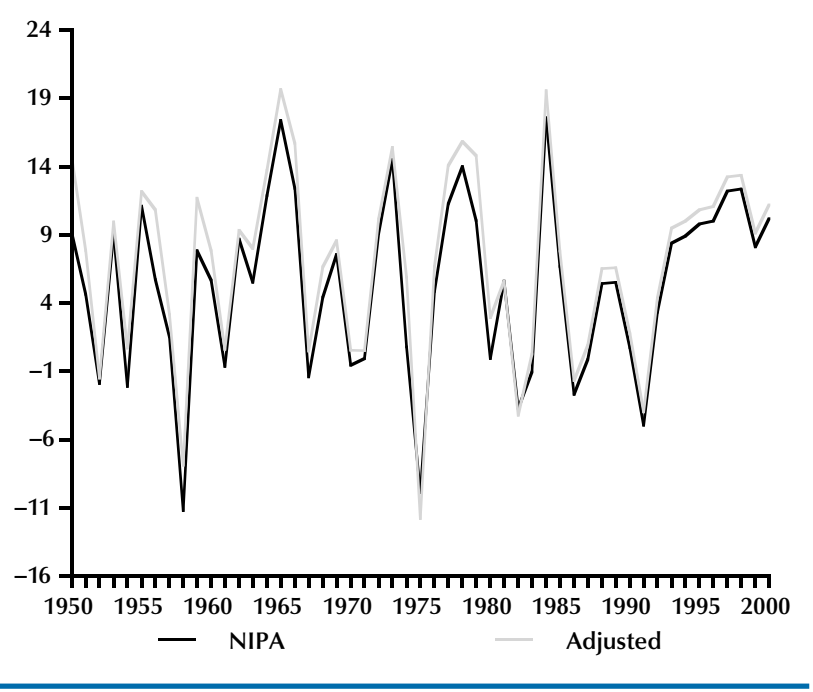

sures are higher than for the official NIPA data, particularly in the earlier decades of the sample period. The contributions of investment growth to GDP growth-across all levels of investment aggregation-show a trend of rising shares of GDP growth. For information processing equipment and software and for ICT spending in particular, sharp increases in the contributions to GDP growth are still evident in the 1990s.

Figures 5 and 6 show the contributions of various investment components to NFI growth and GDP growth, reproducing the time-series forecasting exercises illustrated in Figures 1 and 2. Figure 5 shows that the contributions of information processing equipment and software and ICT investment to total NFI growth both accelerated sharply during the 1990s, as was evident for the unadjusted NIPA data. In this case, however, neither measure exceeds the upper confidence bound associated with the time-series forecast: In the quality-adjusted data, it is no longer the case that the contributions of hightech investment to total investment in the late $1990 \mathrm{~s}$ is significantly higher than would be expected from previous trends and fluctuations in the data. Nevertheless, the contributions of these high-tech components to total investment growth exceed their forecasted paths. For 1996-2000, the contribution of ICT to the quality-adjusted growth rate of total equipment and software spending exceeds predicted values by an average of more than 1.75 percent. 


\section{Figure 5}

\section{Contributions to Growth of Equipment and Software Investment}

Adjusted Data and Forecasts
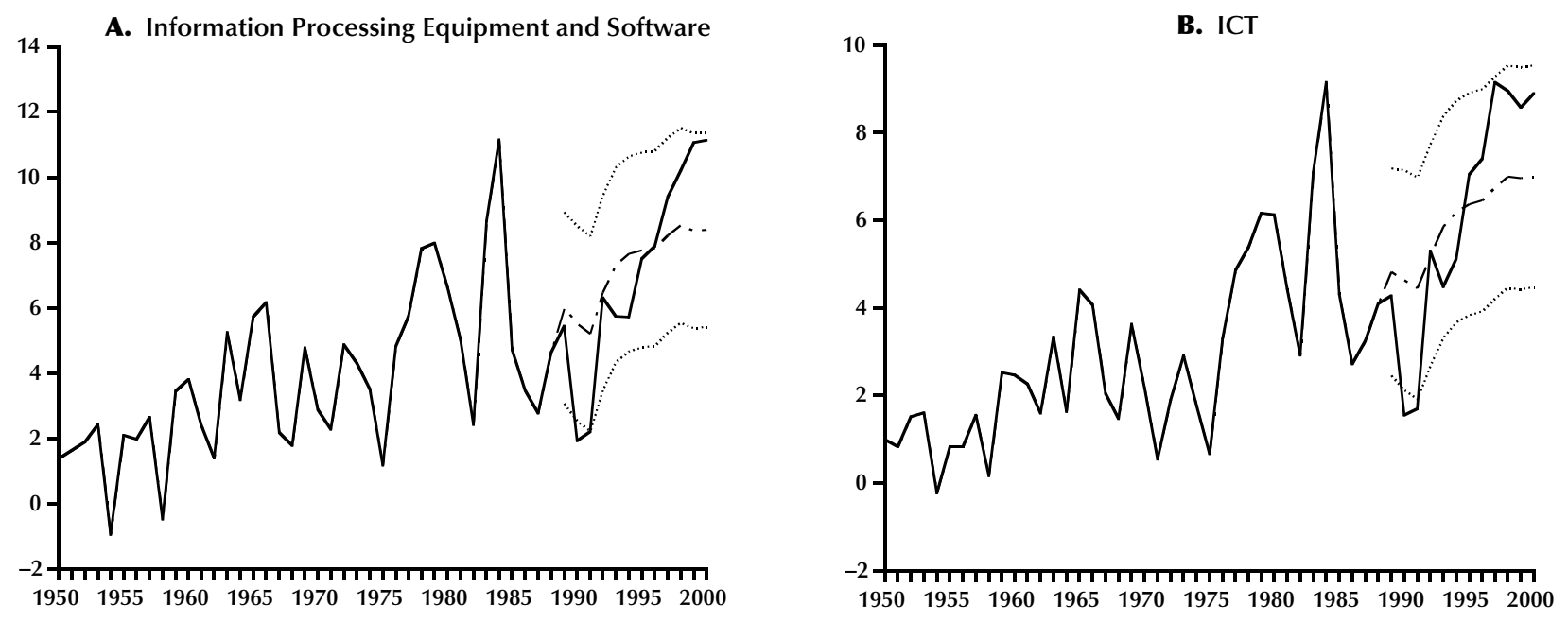

\section{Table 5}

Output and Investment: Growth Rates and Contributions of Investment to GDP Growth for Adjusted Data

\begin{tabular}{|c|c|c|c|c|c|c|}
\hline & 50s & $60 \mathrm{~s}$ & $70 \mathrm{~s}$ & 80s & 90s & 95-00 \\
\hline \multicolumn{7}{|l|}{ Growth rates } \\
\hline GDP & 3.76 & 4.37 & 3.44 & 3.32 & 3.40 & 4.31 \\
\hline Nonresidential fixed investment & 5.49 & 8.33 & 7.45 & 4.31 & 8.87 & 11.60 \\
\hline Structures & 5.19 & 5.52 & 4.49 & 1.85 & 2.66 & 6.49 \\
\hline Equipment and software & 5.78 & 10.08 & 9.15 & 5.73 & 11.23 & 13.37 \\
\hline IP equipment and software & 15.30 & 19.66 & 20.31 & 13.89 & 18.33 & 23.48 \\
\hline ICT & 23.75 & 23.67 & 20.93 & 16.54 & 19.63 & 24.51 \\
\hline \multicolumn{7}{|c|}{$\begin{array}{l}\text { Contribution to GDP growth } \\
\text { Percentage points (percent of GPD growth) }\end{array}$} \\
\hline GDP & $\begin{array}{c}3.76 \\
(100.00)\end{array}$ & $\begin{array}{c}4.37 \\
(100.00)\end{array}$ & $\begin{array}{c}3.44 \\
(100.00)\end{array}$ & $\begin{array}{c}3.32 \\
(100.00)\end{array}$ & $\begin{array}{c}3.40 \\
(100.00)\end{array}$ & $\begin{array}{c}4.31 \\
(100.00)\end{array}$ \\
\hline \multicolumn{7}{|l|}{ Contribution from: } \\
\hline Nonresidential fixed investment & $\begin{array}{c}0.50 \\
(13.18)\end{array}$ & $\begin{array}{c}0.79 \\
(18.15)\end{array}$ & $\begin{array}{c}0.80 \\
(23.25)\end{array}$ & $\begin{array}{c}0.49 \\
(14.90)\end{array}$ & $\begin{array}{c}1.04 \\
(30.45)\end{array}$ & $\begin{array}{r}1.45 \\
(33.63)\end{array}$ \\
\hline Structures & $\begin{array}{c}0.18 \\
(4.85)\end{array}$ & $\begin{array}{c}0.20 \\
(4.61)\end{array}$ & $\begin{array}{c}0.17 \\
(4.87)\end{array}$ & $\begin{array}{c}0.07 \\
(2.13)\end{array}$ & $\begin{array}{c}0.08 \\
(2.23)\end{array}$ & $\begin{array}{c}0.21 \\
(4.91)\end{array}$ \\
\hline Equipment and software & $\begin{array}{c}0.31 \\
(8.33)\end{array}$ & $\begin{array}{c}0.59 \\
(13.54)\end{array}$ & $\begin{array}{c}0.63 \\
(18.38)\end{array}$ & $\begin{array}{c}0.42 \\
(12.77)\end{array}$ & $\begin{array}{c}0.96 \\
(28.22)\end{array}$ & $\begin{array}{c}1.24 \\
(28.71)\end{array}$ \\
\hline IP equipment and software & $\begin{array}{c}0.10 \\
(2.69)\end{array}$ & $\begin{array}{c}0.21 \\
(4.81)\end{array}$ & $\begin{array}{c}0.34 \\
(9.88)\end{array}$ & $\begin{array}{c}0.37 \\
(11.19)\end{array}$ & $\begin{array}{c}0.64 \\
(18.86)\end{array}$ & $\begin{array}{c}0.88 \\
(20.33)\end{array}$ \\
\hline ICT & $\begin{array}{c}0.07 \\
(1.75)\end{array}$ & $\begin{array}{c}0.16 \\
(3.58)\end{array}$ & $\begin{array}{c}0.23 \\
(6.75)\end{array}$ & $\begin{array}{c}0.32 \\
(9.75)\end{array}$ & $\begin{array}{c}0.59 \\
(17.32)\end{array}$ & $\begin{array}{r}0.83 \\
(19.31)\end{array}$ \\
\hline
\end{tabular}




\section{Figure 6}

\section{Contributions to Growth of GDP}

Adjusted Data and Forecasts
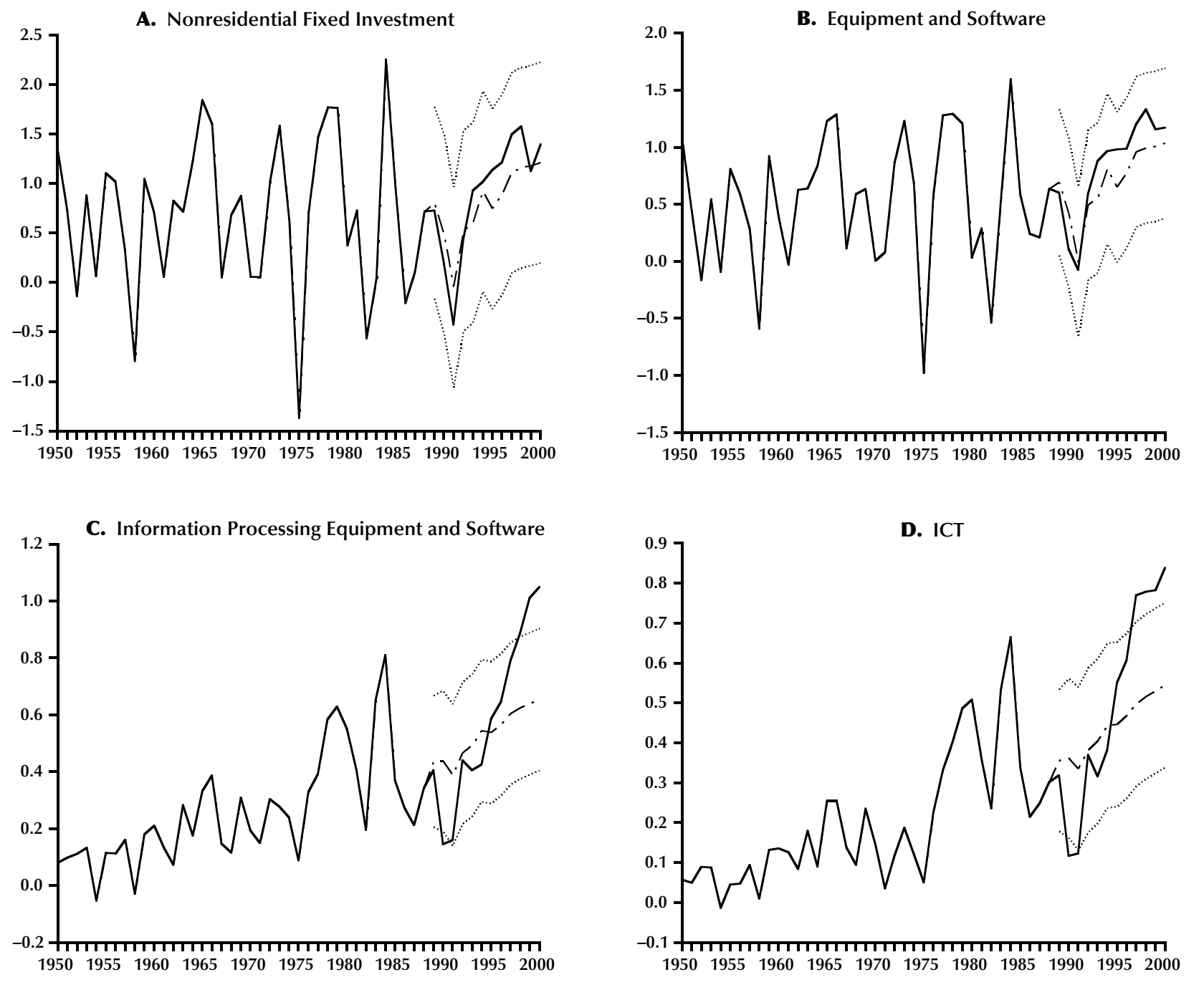

Note also that the magnitudes of the declines in these growth contributions during the 1990-91 recession fall below their forecasted values, as was the case with the unadjusted NIPA data.

Figure 6 shows the contributions of investment spending to GDP growth using the quality-adjusted data. For the broader measures of investment-total private nonresidential investment and total equipment and software investment - the patterns are nearly identical to the unadjusted data: Actual growth contributions fall below their forecasted paths early in the 1990s and exceed the paths later in the decade, but remain well within the confidence bounds.

For the more narrow measures of high-tech investment, the quality adjustment makes somewhat more noticeable difference in the patterns of contributions to GDP growth. Nevertheless, the comparisons of actual to forecasted growth contributions show the same overall relationships as found for the unadjusted data. In the late 1990s, the contribution of high-tech investment spending to overall economic growth was significantly higher than previous data would have suggested. Only the magnitude by which the growth contributions fall outside the forecast confidence intervals is altered by the quality adjustment. 


\section{CONCLUSION}

This article has focused on the issue of quality adjustment in the measurement of investment in the national income and product accounts. The rapidly evolving nature of information processing and communications technologies has necessitated careful accounting of quality improvement in hightech investment sectors. Because it is precisely these sectors which account for the investment boom of the late 1990s, a question arises as to whether it is the measurement of quality improvement itself which accounts for the remarkable growth of the past several years.

This paper addresses that issue by adjusting the investment data for other sources of quality improvement that may have gone unmeasured in the official BEA measures. Although the growth that can be attributed to such unmeasured quality improvement is arguably quite large in some sectors, the variances of investment growth rates are so high that they overwhelm the impact of the quality adjustment. As a result, tests for evaluating how important high-tech investment is in explaining the rapid growth rates of the late 1990s are largely invariant to this accounting for quality. Whether or not one accounts for unmeasured quality change in other capital goods sectors, the contribution of high-tech investment GDP growth in the late 1990s is significantly higher than would have been expected from past patterns of growth and cyclical fluctuations.

Moreover, the contribution of high-tech investment spending to the variability of total investment growth is also reflected in greater-than-forecasted declines in investment during the recession of the early 1990s. Evidently, as ICT technologies have become a more important component of investment spending, they have had the effect of increasing the volatility of investment. In that context, the sharp decline in investment spending seen in 2001 suggests a continuation of this highly variable growth pattern.

\section{REFERENCES}

Court, Andrew T. "Hedonic Price Indexes with Automotive Examples," in The Dynamics of Automobile Demand. New York: General Motors Corporation, 1939, pp. 99-117.

Cummins, Jason G. and Violante, Giovanni L. "EquipmentEmbodied Technical Change in the US (1947-2000): Measurement and Macroeconomic Consequences." Review of Economic Dynamics, 2002 (forthcoming).
Fox, Douglas R. "The U.S. National Income and Product Accounts: Revised Estimates." Survey of Current Business, July 1987, 67(7), pp. 7-15.

and Parker, Robert P. "The Comprehensive

Revision of the U.S. National Income and Product Accounts: A Review of Revisions and Major Statistical Changes." Survey of Current Business, December 1991, 71(12), pp. 24-40

Gordon, Robert J. The Measurement of Durable Goods Prices. Chicago: University of Chicago Press, 1990.

Gort, Michael; Greenwood, Jeremy and Rupert, Peter. "Measuring the Rate of Technological Progress in Structures." Review of Economic Dynamics, January 1999, 2(1), pp. 207-30.

Landefeld, J. Steven and Parker, Robert P. “BEA's Chain Indexes, Time Series and Measures of Long-Term Economic Growth." Survey of Current Business, May 1997, 77(5), pp. 58-68.

and Grimm, Bruce T. "A Note on the Impact of Hedonics and Computers on Real GDP." Survey of Current Business, December 2000, 80(12), pp. 17-22.

and Fraumeni, Barbara M. "Measuring the

New Economy." Survey of Current Business, March 2001, 81(3), pp. 23-40.

Moulton, Brent R. and Seskin, Eugene P. "A Preview of the 1999 Comprehensive Revision of the National Income and Product Accounts: Statistical Changes." Survey of Current Business, October 1999, 79(10), pp. 6-17.

Parker, Robert P. "Recognition of Business and Government Expenditures for Software as Investment: Methodology and Quantitative Impacts, 1959-98." Unpublished manuscript, Bureau of Economic Analysis, 2000. $<$ www.bea.doc.gov/bea/papers/software.pdf > .

Taub, Leon W. and Parker, Robert P. "Preview of Revised NIPA Estimates for 1992 from the 1992 I-O Accounts." Survey of Current Business, December 1997, 77(12), pp. $11-15$.

Triplett, Jack E. “The Economic Interpretation of Hedonic Methods." Survey of Current Business, January 1986, 66(1), pp. 36-40. 


\section{Appendix}

\section{EXTRAPOLATING AND UPDATING THE GORDON DATA}

Of the recent changes to the BEA's definitions and methodology, most apply to the elements of information processing equipment and software. First, the category previously known as office, computing, and accounting machinery (OCAM) was divided into two categories: computers and peripheral equipment and office and accounting equipment. Most of the unmeasured quality change for this component was in the computers and peripherals category, for which a hedonic price index approach was adopted in late 1985. Because current BEA practice carefully accounts for quality change, Gordon's calculations are superfluous for evaluating the growth rate of computer equipment. For the remaining elements of that category, data from Gordon's Tables 6.1 and 6.2 (which detail the construction of a deflator for OCAM) were used to separate out the computer component, with the remaining drift ratio to be applied to the office and accounting machinery component.

Software was incorporated as a component of fixed investment only in 1999, and was therefore not examined by Gordon. The BEA applies a hedonic approach to some components of software investment: In particular, a hedonic index is used to deflate prepackaged software, while in-house software is deflated using an input cost index. Custom software is deflated using a weighted-average of these two deflators. This practice amounts to applying a hedonic price index to about one-half of all software. ${ }^{13}$ For the purpose of this study, I assume that the BEA methodology accurately measures quality change in this component.

Next to computers, the largest drift ratios measured by Gordon were for communications equipment. In particular, Gordon found that the official price index for telephone transmission and switching equipment (by far the largest item in the communications equipment category) vastly understated improvements associated with electronics and transmissions technologies in the 1960s and 1970s. In 1997, the BEA introduced a quality-adjusted price index for telephone switching and switchboard equipment and carried back these revisions to 1985 in the 1999 comprehensive revision of the national accounts. ${ }^{14}$ Because these revisions addressed the most serious concerns that Gordon raised about the measurement of quality change in communications equipment, I assume that the post-1985 data accurately reflect quality improvements. Consequently, I use his drift ratios and extrapolations only for years prior to 1985.

Another category that requires special attention is automobiles. As shown in Table 3, the automobile component showed a negative drift ratio over the 1973-83 period-suggesting that the BEA overestimated quality change over the decade. However, Gordon explains this finding as the result of a "spurious decline in the NIPA automobile deflator during 1980-83" 15 that he attributed to the use of a deflator for used cars that is inconsistent with quality change measured in the index for new cars. (Used cars sold from business enterprises to households - reflecting a reclassification from business capital to consumer durables-represent a factor that subtracts from investment.) In the absence of this inconsistency, Gordon notes that the drift ratio for automobiles would be close to zero for the 1973-83 period. In 1987, the BEA began to adjust used automobile prices by applying a quality-adjustment factor derived from its treatment of new car prices. ${ }^{16}$ In the comprehensive revision of 1991, this change was carried back to years prior to $1984 .{ }^{17}$ This change altered both the nominal and real data series on investment spending for automobiles and largely eliminated the "spurious decline" in the automobile deflator for 1980-83. Consequently, in extrapolating Gordon's data on quality change for autos, I assume a drift ratio equal to zero for the post-1983 period. ${ }^{18}$

Some other reclassifications of the components of equipment investment proved to be simple to address: For example, the reclassification in 1997 of analytical instruments from the "photocopy and related equipment" category to the "instruments"

\footnotetext{
13 See Parker (2000) and Landefeld and Fraumeni (2001).

${ }^{14}$ Moulton and Seskin (1999).

${ }^{15}$ Gordon (1990, p. 538).

${ }^{16}$ Fox (1987).

${ }^{17}$ Fox and Parker (1991).

18 In addition, because the BEA's methodological changes affected both nominal and real series, I use Gordon's actual price index figures (rather than applying his drift ratios directly to the contemporary deflator series) for years prior to 1983.
} 
category required no special adjustments, because Gordon's drift ratio applies to the combined "instruments and photocopy equipment" category that was in use at the time. ${ }^{19}$ Similarly, a reclassification of some equipment from "metalworking machinery" to "special industry machinery" was also innocuous, since Gordon found that the deflator for the latter was based on a subset of raw prices from the former. In calculating his drift ratios, Gordon simply applied the same factor to both categories. ${ }^{20}$

Finally, there is the issue of aggregation technique. At the time of his writing, Gordon criticized the BEA's continuing practice of using fixed-weight deflators. Particularly in light of his modifications accounting for quality change, a fixed-weight approach tends to underestimate the importance of goods that are declining in price (or increasing in quality) while overstating the importance of goods that have rising prices. Gordon proposed the use of a Törnqvist index, which uses share weights from adjacent periods to construct deflators for both the individual components of equip- ment purchases and for aggregating the totals. The BEA subsequently adopted a "Fisher ideal" chainweighting formula that is similar to the Törnqvist approach in that it incorporates share weights from adjacent periods that are allowed to evolve over time. While the two approaches are very similar, they are not identical. For the purposes of this study, however, I assume that the two methodologies are essentially interchangable. While I use Gordon's Törnqvist-aggregated measures for disaggregating and reaggregating the elements of OCAM into their contemporary definitional categories, I use the BEA's chain-weighting formula for aggregating the quality-adjusted components of investment spending into measures that are directly comparable to the NIPA data.

\footnotetext{
19 This reclassification was associated with the incorporation of new data from the 1992 Input-Output accounts. See Taub and Parker (1997).

${ }^{20}$ The "special industry machinery" component was one of six that Gordon referred to as "secondary" categories, for which the underlying price data overlapped with the other 16 "primary" categories.
} 